\title{
Association of $c$-Jun Gene Polymorphism with Susceptibility to Systemic Lupus Erythematosus in a Chinese Population
}

\author{
Yan Ma, ${ }^{1,2, *}$ Jing Tian, ${ }^{1,2, *}$ Han Cen,,2 Jing Li, ${ }^{1,2}$ Wang-Dong $\mathrm{Xu}^{1,2}$ De-Guang Wang, ${ }^{1-3}$ \\ Hai-Feng Pan, ${ }^{1,2}$ and Dong-Qing $Y e^{1,2}$
}

C-Jun has been proved as playing an important role in the pathogenesis of tumors, as a main component of Activator protein 1 and c-Jun gene polymorphisms are associated with colorectal cancer. However, the relationship between the $c$-Jun gene polymorphism and the susceptibility to systemic lupus erythematosus (SLE) has not been known. Our purpose is to evaluate whether the $c$-Jun gene polymorphism (SNP rs3748814) is associated with susceptibility to SLE in a Chinese population. In this study, we enrolled 502 SLE patients and 652 healthy controls. The c-Jun polymorphism (rs3748814) was specified from genomic DNA using the TaqMan genotyping assay on a 7300 real-time reverse transcription polymerase chain reaction system. We found that the frequency of the A/G genotype in SLE patients was lower than in healthy controls, whereas the frequency of the $G / G$ genotype was significantly higher in SLE patients than in healthy controls (A/G vs. G/G $p=8.670 \mathrm{e}-08$, odds ratio $[\mathrm{OR}]=0.290,95 \%$ confidence interval $[\mathrm{CI}]=0.184-0.456$ ). In addition, the frequency of allele $\mathrm{A}$ in the patients group was significantly lower than in the control group (A vs. $G p=5.221 \mathrm{e}-09, \mathrm{OR}=0.308,95 \% \mathrm{CI}=0.212-0.466$ ). The distribution of genotype and allele frequency in SLE patients with lupus nephritis (LN) compared with SLE patients without $\mathrm{LN}$ was not statistically significant (A/G vs. G/G $p=0.744, \mathrm{OR}=1.157,95 \% \mathrm{CI}=0.481-2.785$; A vs. $\mathrm{G} p=0.748, \mathrm{OR}=1.152,95 \% \mathrm{CI}=0.486-2.734 ; \mathrm{A} / \mathrm{A}+\mathrm{A} / \mathrm{G}$ vs. $\mathrm{G} / \mathrm{G} p=0.744, \mathrm{OR}=1.157,95 \% \mathrm{CI}=0.481-2.785)$. Furthermore, we did not find any significant association between other clinical features and genotypes. Our findings suggest that the c-Jun polymorphism (rs3748814) may be significantly associated with the susceptibility to SLE in a Chinese population.

\section{Introduction}

$S$ YSTEMiC LUPUS ERYTHEMATOSUs (SLE) is a prototypic multisystem autoimmune disorder that is characterized by the excessive production of autoantibodies, complement activation, and immune-complex deposition, resulting in tissue and organ damage (Mok and Lau, 2003; Font et al., 2004; Yurasov et al., 2005; Ruiz-Irastorza et al., 2007). Although the etiology and pathogenetic mechanisms of SLE have not been fully understood, evidence has convinced us of a combination of genetic and environmental factors that might be associated with the pathogenesis of SLE (Criswell et al., 2005; Liu et al., 2009). Recently, genetic association studies, especially a genome-wide association study, have suggested that genetic predisposition might play a critical role in the pathogenesis of SLE (Harley et al., 2008; Han et al., 2009).

The transcription factor activator protein 1 (AP-1), including members of Jun, Fos and other activating transcrip- tion factor proteins, is a key component in many signal transduction pathways and plays a critical role in cellular proliferation, differentiation, and apoptosis. It is expressed in many types of cells and can be activated by c-Jun $\mathrm{N}$ terminal kinase, transforming growth factor beta, or Wnt signaling pathway (Zenz et al., 2008). Studies have demonstrated that AP-1 is involved in the pathogenesis of inflammatory bone diseases, autoimmune diseases, and tumors (Han et al., 1998; Wagner and Eferl, 2005; Maritz et al., 2011). Since it is the dominant component of AP-1, the human Jun gene is located on chromosome 1p31-p32, lacks introns, and encodes a protein with 331 amino-acid residues (Haluska et al., 1988; Vogt, 2001). In mammalians, c-Jun can either homodimerize with the Jun family members (Jun JunB, JunD) or heterodimerize with the Fos family members (Fos, FosB, Fra-1, and Fra-2), and c-Jun/c-Fos heterodimer is the most predominant component of AP-1, which has a high AP-1 DNA binding affinity (Lee et al., 2004). Furthermore, a basal level of c-Jun is

\footnotetext{
${ }^{1}$ Department of Epidemiology and Biostatistics, School of Public Health, Anhui Medical University, Hefei, P.R. China.

${ }^{2}$ Anhui Provincial Laboratory of Population Health and Major Disease Screening and Diagnosis, Anhui Medical University, Hefei, P.R. China.

${ }^{3}$ Department of Nephrology, The Second Affiliated Hospital of Anhui Medical University, Hefei, P.R. China.

*These two authors contributed equally to this work.
} 
required for maintaining normal cellular function (Hilberg et al., 1993). c-Jun deficient fibroblasts displayed an obvious proliferation defect in vitro, and c-Jun deficient hepatocytes were severely impaired during liver regeneration in vivo (Zenz et al., 2008). Lately, investigations have revealed that c-Jun may influence the susceptibility of diseases. For instance, Johnson et al. (1993) reported that a c-Jun null mutation could cause embryonic lethality and retard cell growth in mice, and Suto et al. (2004) demonstrated that a dominant-negative mutant of c-Jun had a significant antitumor effect on colorectal cancer both in vitro and in vivo. Moreover, c-Jun polymorphisms in the promoter regions have been discovered as being associated with colorectal cancer (Chen et al., 2011).

However, we know little about c-Jun and SLE to date. Doníz-Padilla et al. (2011) detected a higher expression of c-Jun in peripheral blood mononuclear cells in SLE patients than in controls. Olferiev et al. (2007) found that $c$-Jun might play an important role in the transcriptional regulation of FCGR2B promoter activity, whereas FCGR2B had been demonstrated as being associated with the pathogenesis of SLE. These studies might imply that c-Jun is involved in the pathogenesis of SLE. Consequently, based on the current literature, where there is no report about the c-Jun gene polymorphism in SLE, this study examines whether the c-Jun gene polymorphism (SNP rs3748814 in UTR-5) is associated with the susceptibility to SLE in a Chinese population.

\section{Materials and Methods}

\section{Patients and controls collection and SNPS selection}

A case-control study was conducted that examines the association between the c-Jun gene polymorphism and SLE susceptibility. Five hundred two patients with SLE (37 men and 465 women, mean age $36.16 \pm 11.99$ years) were recruited from the first affiliated hospital of the Anhui Medical University and the Anhui Provincial Hospital. All the patients fulfilled at least four of the American College of Rheumatology (ACR) 1997 Revised Criteria for the classification of SLE (Tan et al., 1982; Hochberg, 1997). Overall, 652 (249 men and 403 women, mean age $34.23 \pm 16.44$ years) healthy controls were enrolled in this study. Venous blood samples were collected from all the subjects for genomic DNA isolation.
The study was approved by the ethics committee of the Anhui Medical University, and informed consent was obtained from all the participants.

In this study, we selected single nucleotide polymorphisms from the international HapMap project databank (www.hapmap.org/) and the Genbank dbSNP database (www.ncbi.nlm.nih.gov), on the basis of a minor allele frequency (MAF) $\geq 0.05$ in the Han Chinese population of Beijing, China. Then, we selected tagging SNP using haploview 4.2 software. Furthermore, SNPs located in the c-Jun functional domain, including UTR-3, UTR-5, synonymous, and nonsynonymous substitutions, were selected. Finally, 2 SNPs were possibly found in the c-Jun gene; we selected an SNP (rs3748814) with a higher MAF from the international HapMap project databank (www.hapmap.org/).

\section{DNA samples and genotyping}

The genomic DNA was extracted from peripheral blood leukocytes using Flexi Gene DNA kits (Qiagen) according to the manufacturer's instructions. Genotyping of SNP was carried out by a TaqMan allele discrimination assay (Applied Biosystems), using an assay-on-demand probe and prime (ID: C_27511276_10 for rs3748814). A polymerase chain reaction (PCR) was used to identify the genotype of the c-Jun (rs3748814) polymorphism. Amplification was performed in a $10 \mu \mathrm{L}$ reaction volume containing $5 \mu \mathrm{L}$ of TaqMan Genotyping master mix, $0.1 \mu \mathrm{L}$ of TaqMan Genotyping assay mix, and $4 \mu \mathrm{L}$ of genomic DNA using a 7300 real-time PCR system (ABI7300; Applied Biosystems). PCR analysis was carried out in 96-well plates on a programmable thermal cycler. The PCR cycling conditions consisted of initial denaturation at $95^{\circ} \mathrm{C}$ for $10 \mathrm{~min}$, followed by 40 cycles at $95^{\circ} \mathrm{C}$ for $15 \mathrm{~s}$ and at $60^{\circ} \mathrm{C}$ for $1 \mathrm{~min}$.

\section{Statistical analysis}

All data were analyzed by Plink 1.06 and SPSS10.01 software (SPSS Inc., 2000). Genotype and allele frequency were compared between the SLE patients and healthy individuals using the chi-square test. The odds ratio (OR) and 95\% confidence interval $(95 \% \mathrm{CI})$ from the genotype and allele frequency were also calculated. The power analysis was

Table 1. Analysis of C-Jun (rs3748814) Genotype, Allele Frequency Between Systemic Lupus Erythematosus Patients and Healthy Controls

\begin{tabular}{|c|c|c|c|c|}
\hline c-Jun (rs3748814) & SLE patients $\mathrm{n}=502(\%)$ & Healthy controls $\mathrm{n}=652(\%)$ & $\mathrm{p}$-value & OR $(95 \% C I)$ \\
\hline \multicolumn{5}{|l|}{ Genotype } \\
\hline $\mathrm{G} / \mathrm{G}$ & $473(94.2)$ & $542(83.1)$ & & reference \\
\hline $\mathrm{A} / \mathrm{G}$ & $29(5.8)$ & $105(16.1)$ & $8.670 \mathrm{e}-08$ & $0.290(0.184-0.456)$ \\
\hline $\mathrm{A} / \mathrm{A}$ & $0(0.0)$ & $5(0.8)$ & 0.999 & NA \\
\hline \multicolumn{5}{|l|}{ Allele frequency } \\
\hline G & $975(97.1)$ & 1189 (91.2) & & reference \\
\hline $\mathrm{A}$ & $29(2.9)$ & $115(8.8)$ & $5.221 \mathrm{e}-09$ & $0.308(0.212-0.466)$ \\
\hline \multicolumn{5}{|l|}{ Dominant model } \\
\hline $\mathrm{G} / \mathrm{G}$ & $473(94.2)$ & $542(83.1)$ & & reference \\
\hline $\mathrm{A} / \mathrm{A}+\mathrm{A} / \mathrm{G}$ & $29(5.8)$ & $110(16.9)$ & $4.011 \mathrm{e}-08$ & $0.302(0.197-0.463)$ \\
\hline \multicolumn{5}{|l|}{ Recessive model } \\
\hline $\mathrm{A} / \mathrm{A}$ & $0(0.0)$ & $5(0.8)$ & & reference \\
\hline $\mathrm{G} / \mathrm{G}+\mathrm{A} / \mathrm{G}$ & $502(100.0)$ & $647(99.2)$ & 0.999 & NA \\
\hline
\end{tabular}

NA, not available; SLE, systemic lupus erythematosus; OR, odds ratio; CI, confidence interval. 
Table 2. Distribution of Genotype and Allele Frequency of C-Jun (rs3748814) in Lupus Nephritis Patients and Systemic Lupus Erythematosus Patients Without Lupus Nephritis

\begin{tabular}{|c|c|c|c|c|}
\hline c-Jun (rs3748814) & Patients with LN $\mathrm{n}=109(\%)$ & SLE without $L N \mathrm{n}=393(\%)$ & p-value & OR $(95 \% C I)$ \\
\hline \multicolumn{5}{|l|}{ Genotype } \\
\hline $\mathrm{G} / \mathrm{G}$ & $102(93.6)$ & $371(94.4)$ & & reference \\
\hline $\mathrm{A} / \mathrm{G}$ & 7 (6.4) & $22(5.6)$ & 0.744 & 1.157 (0.481-2.785) \\
\hline $\mathrm{A} / \mathrm{A}$ & $0(0.0)$ & $0(0.0)$ & NA & NA \\
\hline \multicolumn{5}{|l|}{ Allele frequency } \\
\hline $\mathrm{G}$ & $211(96.8)$ & $764(97.2)$ & & reference \\
\hline $\mathrm{A}$ & $7(3.2)$ & $22(2.8)$ & 0.748 & $1.152(0.486-2.734)$ \\
\hline \multicolumn{5}{|l|}{ Dominant model } \\
\hline $\mathrm{G} / \mathrm{G}$ & $102(93.6)$ & $371(94.4)$ & & reference \\
\hline $\mathrm{A} / \mathrm{A}+\mathrm{A} / \mathrm{G}$ & $7(6.4)$ & $22(5.6)$ & 0.744 & $1.157(0.481-2.785)$ \\
\hline \multicolumn{5}{|l|}{ Recessive model } \\
\hline $\mathrm{A} / \mathrm{A}$ & $0(0.0)$ & $0(0.0)$ & & reference \\
\hline $\mathrm{G} / \mathrm{G}+\mathrm{A} / \mathrm{G}$ & $109(100.0)$ & $393(100.0)$ & NA & NA \\
\hline
\end{tabular}

LN, lupus nephritis.

performed using the statistical program $G^{*}$ Power (Faul et al., 2009). All tests were two tailed, and a $p$-value $<0.05$ was regarded as the level of statistical significance.

\section{Results}

The genotype distribution of healthy controls was in accordance with the Hardy-Weinberg equilibrium. The genotype and allele frequency of c-Jun (rs3748814) in the SLE patients and healthy controls is shown in Table 1 . In the patients group, none of them had the A/A genotype, 29 patients $(5.8 \%)$ had the $\mathrm{A} / \mathrm{G}$ genotype, and 473 patients $(94.2 \%)$ had the $\mathrm{G} / \mathrm{G}$ genotype, the control groups were 5 $(0.8 \%), 105(16.1 \%), 542(83.1 \%)$, respectively. The frequency of the $\mathrm{A} / \mathrm{G}$ genotype was lower in the patients group than in the healthy controls, whereas the frequency of the $G / G$ genotype was significantly higher in the patients group than in healthy controls $(\mathrm{A} / \mathrm{G}$ vs $\mathrm{G} / \mathrm{G} P=8.670 \mathrm{e}-08, \mathrm{OR}=0.290$, $95 \% \mathrm{CI}=0.184-0.456)$. In addition, the patients group showed a decrease in the A allele frequency compared with the controls group (A vs. $\mathrm{G} p=5.221 \mathrm{e}-09, \mathrm{OR}=0.308,95 \%$ $\mathrm{CI}=0.212-0.466)$. We also analyzed the genotype using a dominant and recessive model, and the results showed statistical significance between the patients and controls group $(\mathrm{A} / \mathrm{A}+\mathrm{A} / \mathrm{G}$ vs. $\mathrm{G} / \mathrm{G} p=4.011 \mathrm{e}-08, \mathrm{OR}=0.302,95 \% \mathrm{CI}=$ 0.197-0.463).

Overall, 502 SLE patients were enrolled in the current study, 109 of whom were patients with lupus nephritis (LN). The distribution of genotype and allele frequency in the SLE patients with LN and the SLE patients without LN was compared. The results are shown in Table 2. No statistical significance was found in the SLE patients with LN compared with the SLE patients without LN (A/G vs. G/G $p=0.744, \mathrm{OR}=1.157,95 \% \mathrm{CI}=0.481-2.785 ; \mathrm{A}$ vs. $\mathrm{G} p=0.748$, $\mathrm{OR}=1.152, \quad 95 \% \quad \mathrm{CI}=0.486-2.734 ; \quad \mathrm{A} / \mathrm{A}+\mathrm{A} / \mathrm{G}$ vs. $\mathrm{G} / \mathrm{G}$ $p=0.744, \mathrm{OR}=1.157,95 \% \mathrm{CI}=0.481-2.785)$. The distribution of the genotype of main clinical characteristics in the SLE patients is shown in Table 3 . Nevertheless, no significant association between the other clinical features of SLE and any genotypes was discovered.

Power calculation was performed to assume the sample size for the SLE patients and controls at the 0.05 level of significance. On the basis of these assumptions, we estimated that our study had a statistical power of $92.5 \%$, to detect a true-positive association.

\section{Discussion}

In the present study, we investigated the relationship between the c-Jun gene polymorphism and the susceptibility to SLE in a Chinese population. The results showed that the c-Jun polymorphism (rs3748814) was significantly associated with the susceptibility to SLE. The frequency of the A/G genotype was lower in the patients group than in healthy controls, whereas the frequency of the $G / G$ genotype was significantly higher in the patients group than in healthy controls (A/G vs. G/G $p=8.670 \mathrm{e}-08, \mathrm{OR}=0.290,95 \%$ $\mathrm{CI}=0.184-0.456)$. In addition, the frequency of allele A was

Table 3. Comparison of Other Clinical Characteristics Between c-Jun (rs3748814) Genotypes

\begin{tabular}{lcccrr}
\hline & \multicolumn{5}{c}{ c-Jun $($ rs3748814) $A / G$} \\
\cline { 2 - 6 } & Total $\mathrm{n}=502$ & A/G $\mathrm{n}=29$ & G/G $\mathrm{n}=473$ & p-value & OR (95\% CI) \\
\hline Malar rash, \% & 41.4 & 55.2 & 40.6 & 0.122 & $0.555(0.261-1.181)$ \\
Discoid, \% & 7.4 & 0.0 & 7.8 & 0.118 & - \\
Photosensitivity, \% & 10.2 & 17.2 & 9.7 & 0.193 & $0.517(0.188-1.420)$ \\
Ulcers, \% & 11.6 & 6.9 & 11.8 & 0.419 & $1.813(0.951-1.172)$ \\
Arthritis, \% & 40.2 & 41.4 & 40.2 & 0.897 & $0.951(0.444-2.037)$ \\
\hline
\end{tabular}


significantly lower in the patients group than in the controls group (A vs. $\mathrm{G} p=5.221 \mathrm{e}-09, \mathrm{OR}=0.308,95 \% \mathrm{CI}=0.212-$ 0.466). These findings suggest that the allele A of c-Jun (rs3748814) may be a protective allele against SLE. Since LN is described as being the most serious complication of SLE (Mahmoud et al., 2012), we have attempted to find whether the distribution of the genotype of the c-Jun gene polymorphism (rs3748814) influences SLE severity. The results showed that there was no statistical significance between the patients with LN and the patients without LN (A/G vs. G/G $p=0.744, \mathrm{OR}=1.157,95 \% \mathrm{CI}=0.481-2.785 ; \mathrm{A}$ vs. $\mathrm{G} p=0.748$, $\mathrm{OR}=1.152, \quad 95 \% \quad \mathrm{CI}=0.486-2.734 ; \mathrm{A} / \mathrm{A}+\mathrm{A} / \mathrm{G}$ vs. $\mathrm{G} / \mathrm{G}$ $p=0.744, \mathrm{OR}=1.157,95 \% \mathrm{CI}=0.481-2.785)$. Furthermore, we did not find any significant association between other clinical features and genotypes. These findings indicated that the genotype distribution of c-Jun (rs3748814) might not influence the SLE clinical characteristics.

As we know, autoimmune diseases, such as rheumatoid arthritis and SLE, are considered chronic inflammatory diseases caused by abnormally activated T cells (Goronzy and Weyand, 2004; Charles et al., 2010). More and more studies have indicated that the c-Jun protein may play a key role in Tcell development (Gao et al., 2004; Riera-Sans and Behrens, 2007). However, the influence of the c-Jun polymorphism (rs3748814) on the expression and function of the c-Jun protein has not been studied. In fact, the c-Jun/c-Fos heterodimer is the most predominant component of AP-1 in mammalian cells, and it has a high AP-1 DNA binding affinity (Lee et al., 2004). c-Jun can dimerize through their leucine-zipper domains, which is the key component for activating AP-1, where AP-1 has been substantiated related to the pathogenesis of SLE. In this study, we demonstrate that the c-Jun polymorphism (rs3748814) is associated with the SLE susceptibility. Therefore, genetic variations of $c$-Jun may influence the ability for c-Fos and AP-1 DNA binding affinity, and AP-1 function. However, other studies are needed to verify this relationship in order to further clarify the mechanism of $c$-Jun in the pathogenesis of SLE.

In summary, we investigated the c-Jun polymorphism (rs3748814) and its susceptibility to SLE in a Chinese population based on a case-control study. Our results imply a major influence of C-Jun (rs3748814) on the genetic susceptibility to SLE.

\section{Conclusion}

Our findings suggest that the c-Jun polymorphism (rs3748814) may be significantly associated with the susceptibility to SLE in a Chinese population.

\section{Acknowledgments}

This work was supported by grants from the key program of the National Natural Science Foundation of China (30830089) and the Anhui Provincial Natural Science Foundation (11040606M183). The authors also thank the Division of Rheumatology, the First Affiliated Hospital of the Anhui Medical University, and the Anhui Provincial Hospital, for assistance in the collection of patient samples.

\section{Disclosure Statement}

No competing financial interests exist.

\section{References}

Charles, N., Hardwick, D., Daugas, E., Illei, G.G., and Rivera, J. (2010). Basophils and T helper 2 environment can promote the development of lupus nephritis. Nat Med 16, 701-707.

Chen, D., Song, S., Lu, J., Luo, Y., Yang, Z., Huang, Q., Fu, X., Fan, X., Wei, Y., Wang, J., and Wang, L. (2011). Functional variants of $-1318 \mathrm{~T}>\mathrm{G}$ and $-673 \mathrm{C}>\mathrm{T}$ in $c$-Jun promoter region associated with increased colorectal cancer risk by elevating promoter activity. Carcinogenesis 32, 1043-1049.

Criswell, L.A., Pfeiffer, K.A., Lum, R.F., Gonzales, B., Novitzke, J., Kern, M., Moser, K.L., Begovich, A.B., Carlton, V.E., Li, W., Lee, A.T., Ortmann, W., Behrens, T.W., and Gregersen, P.K. (2005). Analysis of families in the multiple autoimmune disease genetics consortium (MADGC) collection: the PTPN22 $620 \mathrm{~W}$ allele associations with multiple autoimmune phenotypes. Am J Hum Genet 76, 561-571.

Doníz-Padilla, L., Martínez-Jiménez, V., Niño-Moreno, P., AbudMendoza, C., Hernández-Castro, B., González-Amaro, R., Layseca-Espinosa, E., and Baranda-Cándido, L. (2011). Expression and function of Cbl-b in T cells from patients with systemic lupus erythematosus, and detection of the 2126A/G Cbl-b gene polymorphism in the Mexican mestizo population. Lupus 20, 628-635.

Faul, F., Erdfelder, E., Buchner, A., and Lang, A.G. (2009). Statistical power analyses using $G^{*}$ Power 3.1: tests for correlation and regression analyses. Behav Res Methods 41, 1149-1160.

Font, J., Cervera, R., Ramos-Casals, M., Garicia-Carrasco, M., Sents, J., Herrero, C., del Olmo, J.A., Darnell, A., and Inqelmo, M. (2004). Clusters of clinical and immunologic features in systemic lupus erythematosus: analysis of 600 patients from a single center. Semin Arthritis Rheum 33, 217-230

Gao, M., Labuda, T., Xia, Y., Gallagher, E., Fang, D., Liu, Y.C., and Karin, M. (2004). Jun turnover is controlled through JNKdependent phosphorylation of the E3 ligase itch. Science 306, 271-275.

Goronzy, J.J., and Weyand, C.M. (2004). T-cell regulation in rheumatoid arthritis. Curr Opin Rheumatol 16, 212-217.

Haluska, F.G., Huebner, K., Isobe, M., Nishimura, T., Croce, C.M., and Vogt, P.K. (1988). Localization of the human JUN protooncogene to chromosome region 1p32-32. Proc Natl Acad Sci U S A 85, 2215-2218.

Han, J.W., Zheng, H.F., Cui, Y., Sun, L.D., Ye, D.Q., Hu, Z., Xu, J.H., Cai, Z.M., Huang, W., Zhao, G.P., Xie, H.F., Fang, H., Lu, Q.J., Xu, J.H., Li, X.P., Pan, Y.F., Deng, D.Q., Zeng, F.Q., Ye, Z.Z., Zhang, X.Y., Wang, Q.W., Hao, F., Ma, L., Zuo, X.B., Zhou, F.S., Du, W.H., Cheng, Y.L., Yang, J.Q., Shen, Y.J., Zuo, X.X., Zhu, W.F., Gao, F., Zhang, P.L., Guo, Q., Li, B., Gao, M., Xiao, F.L., Quan, C., Zhang, C., Zhang, Z., Zhu, K.J., Li, Y., Hu, D.Y., Lu, W.S., Huang, J.L., Liu, S.X., Li, H., Ren, Y.Q., Wang, Z.X., Yang, C.J., Wang, P.G., Zhou, W.M., Lv, Y.M., Zhang, A.P., Zhang, S.Q., Lin, D., Li, Y., Low, H.Q., Shen, M., Zhai, Z.F., Wang, Y., Zhang, F.Y., Yang, S., Liu, J.J., and Zhang, X.J. (2009). Genome-wide association study in a Chinese Han population identifies nine new susceptibility loci for systemic lupus erythematosus. Nat Genet 41, 1234-1237.

Han, Z., Boyle, D.L., Manning, A.M., and Firestein, G.S. (1998). AP1 and NF-kappaB regulation in rheumatoid arthritis and murine collagen-induced arthritis. Autoimmunity 28, 197-208.

Harley, J.B., Alarcon-Riquelme, M.E., Criswell, L.A., Jacob, C.O., Kimberly, R.P., Moser, K.L., Tsao, B.P., Vyse, T.J., Langefeld, C.D., Nath, S.K., Guthridge, J.M., Cobb, B.L., Mirel, D.B., Marion, M.C., Williams, A.H., Divers, J., Wang, W., Frank, S.G., Namjou, B., Gabriel, S.B., Lee, A.T., Gregersen, P.K., Behrens, T.W., Taylor, K.E., Fernando, M., Zidovetzki, R., Gaffney, P.M., 
Edberg, J.C., Rioux, J.D., Ojwang, J.O., James, J.A., Merrill, J.T., Gilkeson, G.S., Seldin, M.F., Yin, H., Baechler, E.C., Li, Q.Z., Wakeland, E.K., Bruner, G.R., Kaufman, K.M., and Kelly, J.A. (2008). Genome-wide association scan in women with systemic lupus erythematosus identifies susceptibility variants in ITGAM, PXK, KIAA1542 and other loci. Nat Genet 40, 204-210.

Hilberg, F., Aquzzi, A., Howells, N., and Wagner, E.F. (1993). c-Jun is essential for normal mouse development and hepatogenesis. Nature 365, 179-181.

Hochberg, M.C. (1997). Updating the American College of Rheumatololgy revised criteria for the classification of systemic lupus erythematosus. Arthritis Rheum 40, 1725.

Johnson, R.S., van Lingen, B., Papaioannou, V.E., and Spiegelman, B.M. (1993). A null mutation at the c-Jun locus causes embryonic lethality and retarded cell growth in culture. Genes Dev 7, 1309-1317.

Lee, S.Y., Lee, H.S., Moon, J.S., Kim, J.I., Park, J.B., Lee, J.Y., Park, M.J., and Kim, J. (2004). Transcriptional regulation of Zic3 by heterodimeric AP-1 (c-Jun/c-Fos) during Xenopus develpoment. Exp Mol Med 36, 468-475.

Liu, J.L., Zhang, F.Y., Liang, Y.H., Xiao, F.L., Zhang, S.Q., Cheng, Y.L., Yuan, C.D., Chen, Q.P., Yang, S., and Zhang, X.J. (2009). Association between the PD1.3A/G polymorphism of the PDCD1 gene and systemic lupus erythematosus in European populations: a meta-analysis. J Eur Acad Dermatol Venereol 23, 425-432.

Mahmoud, S.S., Bazaraa, H.M., Lotfy, H.M., and Abd-El-Aziz, D.M. (2012). Renal involvement in childhood-onset systemic lupus erythematosus in Egypt. Rheumatol Int 32, 47-51.

Maritz, M.F., van der Watt, P.J., Holderness, N., Birrer, M.J., and Leaner, V.D. (2011). Inhibition of AP-1 suppresses cervical cancer cell proliferation and is associated with p21 expression. Biol Chem 392, 439-448.

Mok, C.C., and Lau, C.S. (2003). Pathogenesis of systemic lupus erythemaosus. J Clin Pathol 56, 481-490.

Olferiev, M., Masuda, E., Tanaka, S., Blank, M.C., and Pricop, L. (2007). The role of activating protein 1 in the transcriptional regulation of the human FCGR2B promoter mediated by the -343G->C polymorphism associated with systemic lupus erythematosus. J Biol Chem 282, 1728-1746.
Riera-Sans, L., and Behrens, A. (2007). Regulation of alphabeta/ gammadelta $\mathrm{T}$ cell development by the activator protein 1 transcription factor c-Jun. J Immunol 178, 5690-5700.

Ruiz-Irastorza, G., Khamashta, M.A., Castellino, G., and Hughes, G.R. (2007). Systemic lupus erythematosus. Lancet 357, 1027-1032.

Suto, R., Tominaga, K., Mizuguchi, H., Sasaki, E., Higuchi, K., Kim, S., Iwao, H., and Arakawa, T. (2004). Dominant-negative mutant of c-Jun gene transfer: a novel therapeutic strategy for colorectal cancer. Gene Ther 11, 187-193.

Tan, E.M., Cohen, A.S., Fries, J.F., Masi, A.T., McShane, D.J., Rothfield, N.F., Schaller, J.G., Talal, N., and Winchester, R.J. (1982). The 1982 revised criteria for the classification of systemic lupus erythematosus. Arthritis Rheum 25, 1271-1277.

Vogt, P.K. (2001). Jun, the oncoprotein. Oncogene 20, 2365-2377. Wagner, E.F., and Eferl, R. (2005). Fos/AP-1 proteins in bone and the immune system. Immunol Rev 208, 126-140.

Yurasov, S., Wardemann, H., Hammersen, J., Tsuiji, M., Meffre, E., Pascual, V., and Nussenzweig, M.C. (2005). Defective B cell tolerance checkpoints in systemic lupus erythematosus. J Exp Med 201, 703-711.

Zenz, R., Eferl, R., Scheinecker, C., Redlich, K., Smolen, J., Schonthaler, H.B., Kenner, L., Tschachler, E., and Wagner, E.F. (2008). Activator protein 1 (Fos/Jun) functions inflammatory bone and skin disease. Arthritis Res Ther 10, 201.

Address correspondence to: Dong-Qing Ye, M.D. Department of Epidemiology and Biostatistics School of Public Health Anhui Medical University 81 Meishan Road Hefei 230032 P.R. China

E-mail: ydq@ahmu.edu.cn

Received for publication November 15, 2011; received in revised form February 13, 2012; accepted February 13, 2012. 